\title{
Inhibitory Effects of Grape Seeds Powder, Extract and Oil on Gentamicin Induced Nephrotoxicity in Rats
}

\author{
Nagib, R.M \\ Home Economics Dept., Faculty of Specific Education, Mansoura University, \\ Mansoura, Egypt
}

\begin{abstract}
This study was designed to determine the Inhibitory effect of grape seeds powder, extract and oil on gentamicin-induced nephrotoxicity in rats. The study was carried out on 30 adult albino male rats Sprague-Dawley strain were classified into two groups: The first group $(n=6)$ left as normal control group(-ve), fed on basal diet, the second group $(n=24)$ injected with gentamicin $(100 \mathrm{mg} / \mathrm{kg} /$ day for 7 days i.p). These animals were divided into 4 groups 6 rats each of these, control (+ve) group and 3 groups were treated with grape seeds powder ( $10 \%$ of diet ), grape seeds extract ( $300 \mathrm{mg} / \mathrm{kg}$ b.w.orally by stomach tube) and grape seeds oil ( $4 \mathrm{ml} / \mathrm{kg} \mathrm{b.w.} \mathrm{orally} \mathrm{by} \mathrm{stomach} \mathrm{tube)} \mathrm{respectively.}$ The treatment period was designed for eight weeks. The results revealed that, Gentamicin injection induced marked nephrotoxicity as evidenced by significant elevation in serum levels of creatinine, urea, uric acid, A/G ratio, MDA, renin hormone, phosphorus and potassium, with significant reduction in serum levels of total protein, albumin, globulin, (SOD), (GPX), (GST), catalase antioxidant enzymes, erythropoietin hormone (EPO), vitamin D and Ca. While the rat groups treated with grape seeds powder, extract and oil showed significant improvement of the levels of serum total protein, albumin, globulin, kidney tissue superoxide dismutase (SOD), glutathione peroxidase (GPX), glutathione transferase (GST), catalase antioxidant enzymes, erythropoietin hormone (EPO) and vitamin D, and significant decrease in serum creatinine, urea, uric acid, albumin/globulin ratio ,kidney tissue malondialdehyde (MDA), renin hormone, phosphorus and potassium compared with control(+ve) group. In conclusion, feeding rats with grape seeds powder, extract and oil may significantly reduce nephrotoxicity, So this study recommend the use of grape seeds especially grape seeds oil or grape seeds extract for humans suffering nephrotoxicity, could be of value.
\end{abstract}

Key words : Grape seeds, Grape seeds extract, Oil, Nephrotoxicity, kidney damage, Gentamicin, Rats.

\section{Introduction}

Antibiotics are the most widely used drugs. These drugs can prevent many problems caused by infections. However, antibiotics can have side effects and damage various body organs, including the liver, kidney, brain, blood, skin, eyes, mouth and others (Ayatollahi, 2005).

Gentamicin (GM) is an aminoglycoside antibiotic, used to treat many types of bacterial infections, particularly those caused by gram-negative bacteria (Nykjaer et al.,2009). It is highly effective against gram negative bacilli with a concentration dependent antibacterial action and post-antibiotic effect (ability to suppress bacterial growth for a period of time after the drug level has fallen below the minimal inhibitory concentration (MIC) of the bacteria) (Wiesenfeld and 
Heine,1998). Aminoglycosides, like GM have been widely used in clinical situations because of its efficacy and low cost. However, aminoglycosides present a serious drug induced nephrotoxicity which is linked to their accumulation in renal cortex and their capacity to bind the phospholipids and to induce intracellular lesions. Evidence suggests that aminoglycoside induced nephrotoxicity occurs after few days of therapy( Sweileh, 2009).

Nephrotoxicity is a major complication characterized by functional alterations including inhibition of protein synthesis, reduced glutathione depletion, lipid peroxidation and mitochondrial damage. Oxidative damage is thought to be one of the main mechanisms involved in nearly all chronic renal pathologies. Administration of gentamicin to rats induced a marked renal failure, characterized with a significant increase in plasma creatinine and urea concentrations. A significant increase in kidney MDA and a decrease in GSH concentrations were observed in gentamicin-treated rats ( Fauconneau et al .,1995).

Grape seed extract has long been recognized to possess many properties, including antioxidant, antiinflammatory, anticarcinogenic, platelet aggregation inhibiting, and metal chelating properties (Bagchi et al .,1998).

Grape seeds which are produced of grape fruit industries contain polyphenol members of the family of proanthocyanidins. Structurally, the proanthocyanidins are a group of complex compounds made up of oligomers and polymers of polyhydroxyflavan-3-ol monomer units( Rice-Evans et al., 1996). Grape seeds also contain lipids, protein, carbohydrates, besides $5 \%$ to $8 \%$ polyphenols, mainly flavonoids including gallic acid, the monomeric flavan-3-ols catechin, epicatechin, gallocatechin, epigallocatechin, and epicatechin 3-O-gallate, and procyandin, dimers, trimers and more highly polymerized procyanidins. (Shi et al., 2003).

Grape seeds powder is an effective anti-aging drug in preventing the oxidative stress associated loss of membrane surface charge, which thereby maintains the erythrocyte membrane integrity and functions in elderly (Purushotham et al., 2005).

Grape seeds extracts contain exceptionally high amounts of total polyphenols $(10.3-11.1 \%$ on a dry weight basis), and indicate that wine industry by-products, including grape seeds but also red grape pomace and stems, are very rich sources of antioxidant polyphenols compared with other agri-food solid wastes, and therefore their exploitation as a source of added-value products may be more cost-effective and merits a profounder investigation (Dimitris et al., 2007) .

Grape seed oil has a very high level of antioxidant vitamin E (60-120 mg/100g), which makes the oil very stable. The antioxidant property is claimed to be the mechanism of hepatoprotective activity. The grape seed oil exhibits a variety of interesting properties such as reducing platelet aggregation, prevents hypertension caused by sodium excess, and normalizes lesions occurring from obesity and diabetes (Bagchi et al., 2002). Grape seed oil contains tannins at levels higher than other seed oils $0.8-1.5 \%$ unsaponifiable lipids, mainly esterols as $\beta$-sitosterol, campesterol and stigmasterol (Rao, 1994).

The objective of this study was to investigate the inhibitory effect of grape seeds consumption either as powder, extract or oil against gentamicin induced nephrotoxicity in rats. 


\section{Egypt. J. of Nutrition and Health Vol. 9 No. 1 (2014)}

\section{Materials and Methods}

\section{Materials:}

Grape seeds (Vitis vinifera): Grape samples were obtained from local market in Mansoura city, Egypt. The grape were taken and washed with tap water, then particles of skins and pulp adhering to the seeds were removed by hand, and the seeds were washed with tap water, dried in air then grinded into fine powders and saved in polyethylene bag and stored under freezing.

Gentamicin: Gentamicin (Garamycin ${ }^{\circ}$ injection), an amino glycoside antibiotic, was obtained from Memphis Company for Pharmaceutical and Chemical Industries, Cairo, Egypt. It is dispensed in the form of ampoules, each containing 40 $\mathrm{mg} / \mathrm{mL}$ of gentamicin sulphate. Gentamicin is given to rats in dose a $100 \mathrm{mg} / \mathrm{kg} / \mathrm{day}$ for 7 days intraperitoneally for inducing renal damage according to previous studies as reported by (Farombi and Ekor 2006).

Experimental Animals: Thirty male albino rats of Sprague Dawley strain were purchased from Laboratory Animal Colonies, Pharmacology Departement Faculty of Medicine, Mansoura Universty. The average weight was $140 \pm 10 \mathrm{~g}$.

Standard Diet: Standard diet was prepared according to (NRC, 1995).

Kits : were obtained from Biodiagnostic Co. Egypt.

Chemicals: were purchased from El-Gomhorya Company, El-Mansoura city, Egypt.

\section{Methods:}

Extraction of the hydro-alcoholic extracts:

The extraction procedure for the hydro-alcoholic extract was carried out according to Charles et al.(1993), $250 \mathrm{~g}$ of sample under investigation were macerated in one liter of ethanol overnight at room temperature, then filtered and the crude extract was collected. Another portion of $1000 \mathrm{ml}$ of ethanol were added to each residue of samples and boiled for $2 \mathrm{~h}$ under refluxing in a water bath and then filtered. The filtrate was collected to the previous crude extract. In the same manner $1000 \mathrm{ml}$ portion of distilled water were added to each residue of samples and left at room temperature overnight, then filtered. The filtrate was added to the previous crude extract. Another volume of distilled water was added to the residue, boiled for $2 \mathrm{~h}$ under reflux condenser, and filtered. The hot water filtrate was added to the previous crude extract to form the hydro-alcoholic crude extract. Each of hydro-alcoholic extracts was evaporated to dry under reduced pressure at $60 \mathrm{oC}$, and then the dried hydro-alcoholic extracts were individually kept in dark bottles and stored in a deep freezer until usage.

Oil extraction: Grape seeds powder was de-oiled with hexane (one part powder to 10 parts hexane, w/v). The mixture was shaken for 10 minutes at room temperature and left at room temperature over night; the extract was separated from the solid by Buckner apparatus. The residue was re-extracted with the same solvent four times, and then the solvent removed under reduced pressure by using a rotary evaporator. 
Chemical Study: Moisture, protein, fat and ash of grape seeds were determined according to the methods of the (AOAC 2000), while total carbohydrates were calculated by difference as following: Carbohydrates $\%=100-($ moisture $\%+$ protein $\%+$ fat $\%$ +ash $\%$ ).

Experimental Rats Design: Rats were kept under observation for seven days for adaptation and fed on standard diet.Then 6 rats kept as normal control group and 24 rats were injected with gentamicin in dose a $100 \mathrm{mg} / \mathrm{kg} / \mathrm{day}$ for 7 days intraperitoneal to induce renal damage and classified into control positive group and 3 treated rat groups, One group was treated with grape seeds powder( $10 \%$ of diet), The second group was treated with grape seeds extract ( $300 \mathrm{mg} / \mathrm{kg} \mathrm{b.w.} \mathrm{orally} \mathrm{by} \mathrm{stomach} \mathrm{tube)} \mathrm{and} \mathrm{the} \mathrm{third} \mathrm{group} \mathrm{was} \mathrm{treated} \mathrm{with} \mathrm{grape} \mathrm{seeds} \mathrm{oil} \mathrm{(4} \mathrm{ml/kg} \mathrm{b.w.} \mathrm{orally} \mathrm{by}$ stomach tube) according to Maheswari and Rao (2005). Food and water was provided ad-libtum. Food intake was recorded daily and body weight of rats was measured once weekly. At the end of the experimental period (eight weeks), the rats were anaesthetized by diethyl ether and sacrificed. Blood samples were collected from jugular vein and centrifuged at 3000rpm for $15 \mathrm{~min}$ to obtain serum. Animals were quickly dissected and the kidney samples were immediately removed, washed, minced and homogenized in ice-cold sodium, potassium phosphate buffer $(0.01 \mathrm{M}, \mathrm{pH}$ 7.4) containing $1.15 \% \mathrm{KCl}$ in homogenizer. The homogenates were centrifuged at $3000 \mathrm{rpm}$ for 15 min for further biochemical analysis.

Laboratory Analysis: Serum creatinine, urea and uric acid were estimated according to Bonsens and Taussky (1984), Patton and Crouch, (1977) and Fossati et al. (1980), respectively. Serum total protein, albumin and globulin were determined as described by the method of Weichselbaum (1946), Bartholomev and Delany (1966), and Coles (1974), respectively. Kidney superoxide dismutase (SOD), glutathione peroxidase (GPX), glutathione transferase (GST), malondialdehyde (MDA) and catalase were determined according to Beuchamp and Fridovich (1971), Tapple (1978), Moran et al. (1979), Uchiyama and Mihara (1978) and Cohen et al. (1970), respectively. Renin and erythropoietin (EPO) renal hormone and vitamin D were estimated according to Van-Kats et al. (2001), Vale rie et al. (2006) and Wilkie et al. (1958) respectively. Estimation of some serum mineral ( $\mathrm{Ca}, \mathrm{P}$ and $\mathrm{K}$ ) samples according to Pupsa et al.(1994).

Calculation of Some Parameters: Food efficiency ratio was determined according to the method of Chapman et al (1950), while albumin/globulin (A/G) ratio was calculated using albumin and globulin values for each individual sample.

Statistical Analysis: The obtained data were statistically analyzed using computerized SPSS (Statistic Program Sigmastat, Statistical Soft-Ware, SAS Institute, Cary, NC). Effects of different treatments were analyzed by one way ANOVA (Analysis of variance) test using Duncan's multiple range test and $p<0.05$ was used to indicate significance between different groups (Snedecor and Cochran, 1967).

\section{Results and Discussion}

The chemical composition of grape seeds was illustrated in Table 1. The main constituents of grape seeds were moisture which was $(5.98 \mathrm{~g} / 100 \mathrm{~g})$ and ash was $(2.62 \mathrm{~g} / 100 \mathrm{~g})$. The value of protein $(7.51 \mathrm{~g} / 100 \mathrm{~g})$ but the value of fat was $(18.23 \mathrm{~g} / 100 \mathrm{~g})$ while the value of carbohydrate $(65.66 \mathrm{~g} / 100 \mathrm{~g})$. The results of elementary chemical composition of grape seeds agreed with those reported by Kamel et al., (1985) revealed that grape seeds, comprise 20 to $26 \%$ of the pomace, have a high protein content. They also have 10 to $20 \%$ oil, with high vitamin E content, which has very 


\section{Egypt. J. of Nutrition and Health Vol. 9 No. 1 (2014)}

important effects on human health. Grape seed oil mainly consists of triglycerides (TG), which are rich in unsaturated fatty acids, such as oleic and linoleic acids, compared to other oil-rich seeds. The poly-unsaturated fatty acids such as linoleic and linolenic acids are essential for the human metabolism because of the lack of enzymes responsible for synthesis of these fatty acids. For this reason, they could be used as foods, and so its oil (Barron et al., 1988; Schuster, 1992 and Ohnishi et al., 1990).

The statistical data in Table 2 showed that, Gentamicin induced nephrotoxicity rat group (control + ve) showed a significant decrease in final body weight, body weight gain and food efficiency ratio compared with normal control (-ve) group. The rat groups treated with grape seeds powder, extract and oil showed a non significant difference in weight gain ,food intake and FER compared with normal group but showed a significant increase in final body weight, body weight gain and food efficiency ratio compared with control(+ve) group.The results are in agreement with Maldonadu et al., (2003) who revealed that the significant and progressive weight loss in gentamicin treated rats may possibly be due to the injury of renal tubules and the subsequent loss of the tubular cells to reabsorb water, leading to dehydration and loss of body weight. Polyphenols present in grape seed might have reduced food intake and prevented weight gain. In vitro experiments showed that polyphenols stimulated lipolysis, which is hypothesized to be particularly effective in overweight subjects who might show a reduced lipolysis (Tebib et al., 1996; Ardevol et al., 2000 and Fisher et al., 2002). The efficacy of grape-seed extract may be effective in reducing energy intake, while satiety is sustained. The mechanism of grape seed in the short term could be due to delayed absorption of the diet, which might support sustained satiety while subjects ingest less food (Langhans and Scharrer, 1987; McCarty and Scharrer, 1994 and Kamphuis et al., 2003).Grape seed oil is an important source for the production of conjugated linoleic acid (CLA), which has demonstrated to reduce body fat in several animal models, independent of the type or quantity of dietary fat consumed (LuqueRodriguez et al., 2005).

The results in Table 3 indicated that control (+ve) rat group showed a significant increase in levels of creatinine, urea , uric acid and albumin /globulin ratio but showed a significant decrease in total protein, albumin and globulin compared with normal control (-ve) group, The rat groups treated with grape seeds powder and extract showed a significant increase in creatinine, While The rat groups treated with grape seeds oil showed non significant difference in creatinine compared with normal group. The rat groups treated with grape seeds powder showed a significant increase in urea, While the rat groups treated with grape seeds extract and oil showed non significant difference in urea compared with normal control (-ve) group. The rat groups treated with grape seeds powder and extract showed a significant increase in uric acid and showed a significant decrease in total protein compared with normal control (-ve) group, The rat group treated with grape seeds oil showed significant decrease in uric acid and showed a significant increase in total protein compared with normal control (-ve) group. The rat groups treated with grape seeds powder ,extract and oil showed significant decrease in albumin and albumin /globulin ratio but showed a significant increase in globulin compared with normal control (-ve) group. On the other hand there was a significant decrease in levels of creatinine, urea , uric acid and albumin /globulin ratio but showed a significant increase in total protein, albumin and globulin in rat groups treated with grape seeds powder, extract and oil compared with control (+ve) group. This explanation is in line with the study by Hala (2012) who revealed that administration of gentamicin induced a marked renal failure, characterized with reduced glomerular function, while is reflected by marked significant increase in the serum levels of creatinine, urea and uric acid concomitant with significant decrease in serum levels of total protein. Catechin analogues such as (-) -epicatechin 3-o-gallate (ECG) and EGCG found in grape seed extract are known to have many physiological 


\section{Nagib, R.M}

effects, such as to exert suppressive effects on renal failure (Nakagawa et al., 2004; Yamabe et al., 2006). The free radical scavenging ability of proanthocyanidins and flavonoids present in grape seed extract (Sato et al., 2005) may account for the nephroprotective action of grape seed extract against gentamicin induced nephrotoxicity. Similar results were reported in a study by Yousef et al., (2009) in which renal toxicity was caused by cisplatin and grape seed extract was used for protection. Thus, grape seed extract indirectly corrects body homeostasis through its improvement of kidney function. In addition to those studies they studied the nephrotoxocity of grape seed extract and reported that grape seed extract has no nephrotoxicity (Abd El-wahab et al., 2008). The current study proved that grape seeds extract and oil have nephroprotective effect too, where; grape seeds extract and oil could return back the creatinine and urea levels to normal and significantly reduced the elevation in uric acid level.

The results in Table 4 indicated that control (+ve) rat group showed significant decrease in kidney SOD, GPX, GST and catalase but showed a significant increase in kidney MDA compared with normal control (-ve) group, The rat groups treated with grape seeds powder and extract showed a significant decrease in kidney SOD and GPX, While The rat group treated with grape seeds oil showed significant increase in kidney SOD and GPX compared with normal control (-ve) group. The rat groups treated with grape seeds powder, extract and oil showed significant decrease in kidney GST and catalase, while it showed a significant increase in kidney MDA compared with normal control (-ve) group. On the other hand the rat groups treated with grape seeds powder, extract and oil showed significant increase in kidney SOD, GPX, GST and catalase while it showed a significant decrease in kidney MDA compared with control (+ve) rat group. The results are in agreement with Yang et al ., (1995) who reported that Gentamicin increased superoxide anion production, hydrogen peroxide and hydroxyl radicals by kidney mitochondria. Free radicals cause peroxidation of membrane phospholipids, protein denaturation and DNA chain break. Most significant biological damage by reactive oxygen metabolites are reaction with unsaturated lipid peroxidation and thus their peroxidation. This effect caused changes in membrane fluidity and finally membrane molecules are permeable to even as large as enzymes (Inoue and Kawanishi., 1995).A significant increase in kidney MDA and a decrease in glutathione concentrations were observed in gentamicin treated rats and severe proximal renal tubular necrosis followed by renal failure (Fauconneau et al., 1995). Antioxidants are compounds that act as inhibitors of the oxidation process and are found to inhibit oxidant chain reaction at small concentration and thereby eliminate the threat of pathological processes. Phenolic compounds present in medicinal plants have been reported to possess powerful antioxidants activity (Maldonadu et al ., 2003). Grape seeds are rich sources of monomeric phenolic compounds such as catechin, epicatechin and dimeric, trimeric and tetrameric proanthocyanidins (Shin et al., 2010). These molecules possess a structure that confers on them an antioxidant property, which has been demonstrated to exert a novel spectrum of biological, pharmacological, therapeutic, and chemoprotective effects against oxygen free radicals and oxidative stress, which can be used as herbal remedies especially for controlling oxidative damages (El-Ashmawy et al., 2007and Dulundu et al., 2007). Several studies have indicated that extracts obtained from grape seed inhibit enzyme systems that are responsible for the production of free radicals, and that they are antimutagenic and anticarcinogenic (Pinheiro et al., 2010). For this reason, grape seed extract is widely consumed as a dietary supplement in addition to the chemotherapeutic agents in cancer treatment (Çetin et al., 2008).

Grape seed extracts have been reported to possess a broad spectrum of pharmacological, and therapeutic effects including anti-inflammatory activity and reduced apoptotic cell death (Ashtiyani et al., 2013). Grape seed extracts are known to have high antioxidant activity and contain numerous polyphenols. The polyphenols have been shown to 


\section{Egypt. J. of Nutrition and Health Vol. 9 No. 1 (2014)}

have positive effects on vascular injury, it is also known to have free radicals scavenging and antimutagenic activity (Çetin et al., 2008). Grape seeds oil is an extract by-product obtained from the grape seed and it contains a variety of biologically active species used for protection against oxidative stress induced by free radicals and ROS (Baiges et al., 2010 and Ashtiyani et al., 2013). In relation to their polyphenol compounds, GSO contains mainly flavonoids, all involved in ameliorating the oxidative stress in vitro and in vivo through their ability to balance the oxidant-antioxidant status (Sehirli et al., 2008). Procyanidolic oligomers (leucocyanidines, LCs) extracted from grape seeds are known to have antioxidant and antimutagenic activities, and a protective effect against cardiovascular disease. Administration of LCs markedly decreased the activities of NADPH-cytochrome P450 reductase, P4501A1, P4501A2, and P4503A4, but significantly increased the activities of glutathione S-transferase and phenolsulfotransferase in rat liver. However, the activities of antioxidant enzymes were not affected by LC administration. The inhibition of P450s and increases in phase II enzyme activities indicate a role for LCs as a chemopreventive agent against toxic or carcinogenic metabolites of P450 isozymes (Seo-Kyung et al., 2001).

The statistical data in Table 5 presented that, control (+ve) rat group showed significant increase in renin hormone but showed a significant decrease in erythropoietin (EPO) renal hormone and vitamin D compared with normal control (-ve) group, The group treated with grape seeds powder showed a significant increase in renin hormone, While The groups treated with grape seeds extract and oil showed significant decrease in renin hormone compared with normal control (-ve) group. The groups treated with grape seeds powder, extract and oil showed significant decrease in erythropoietin (EPO) renal hormone and vitamin D compared with normal control (-ve) group. On the other hand the groups treated with grape seeds powder, extract and oil showed significant decrease in renin hormone but showed a significant increase in erythropoietin (EPO) renal hormone and vitamin D compared with the control (+ve) rat group. The results are in agreement with $\mathrm{Li}$ et al, (2002) and Yuan et al,(2007) who revealed that renin angiotensin system (RAS) in the kidney is a mandatory mediator of renal injury. Vitamin D hormone has a negative regulatory effect on renin angiotensin system by suppressing renin expression. It is shown that vitamin D receptor-absent mutant mice develop more severe renal damage (e.g., interstitial fibrosis, increased albuminuria, and glomerulosclerosis) than wild-type counterparts in diabetic state Zhang et al,(2008) or under postrenal acute kidney injury, because of enhanced activation of the RAS in the kidney (Zhang et al., 2010). Gentamicin induced kidney damage is linked with lipid peroxidation, and protein oxidation in the renal cortex with reducing activity of renal antioxidant enzymes (Stojiljkovic et al., 2008 and Lopez-Novoa et al., 2011). Grape seed extract (GSE) contains several active components including flavonoids, polyphenols, anthocyanins, proanthicyanidins and procyanidines, It contains $70-95 \%$ standardized proanthocyanidins (Ferreira and Li, 2000).

These flavonoids have demonstrated a marked spectrum of biological, pharmacological, therapeutic, and chemoprotective properties against oxygen free radicals and oxidative stress. Grape seed proanthocyanidin extract (GSPE) has more powerful antioxidative activity than other well-known antioxidants, including vitamin C, vitamin E, and gallic acid (Ariga, 2004). GSPE has various biological functions including antiaging, potent phytochemical antioxidants, antibacterial, antiviral, antiinflammatory, anti-allergic, and vasodilatory actions. Various reports have shown that long term dietary supplementation of polyphenols improved the cognitive performance in aged rats (Alia et al., 2003; Balu et al., 2006; Abdelgawad et al., 2012). 


\section{Nagib, R.M}

The statistical data in Table 6 presented that the control (+ve) rat group showed significant decrease in serum Ca while showed significant increase in serum $\mathrm{P}$ and $\mathrm{K}$ values compared with normal control (-ve) group. The groups treated with grape seeds powder, extract and oil showed non-significant changes in serum Ca while showed significant decrease in $\mathrm{P}$ and $\mathrm{K}$ values compared with the (+ve ) control group. The results are in agreement with Finn( 1977) and Laurent et al., (1988) who revealed that kidneys are responsible for the elimination of metabolic waste and the control of the amount and composition of the body fluids. Nephrotoxicity can result in systemic toxicity causing: decreased ability to excrete body wastes, inability to maintain body fluid and electrolyte balance and decreased synthesis of essential hormones. Gentamicin increases generation of reactive oxygen species (ROS) such as superoxide anions, hydroxyl radicals, hydrogen peroxide, and reactive nitrogen species in the kidney (Balakumar et al., 2008).

Kidneys play a central role in the regulation the balance of body salt and water, hence disordered regulation of renal functions is responsible for the altered balance of salt and water. The increase of Potassium appeared to be due to reduced excretion of $\mathrm{K}$ aggravated by leakage of intracellular potassium into blood stream as a result of gentamicin induced lesions in renal tubular epithelium (Heibashy \& Abdel Moneim, 1999). Serum phosphorus was significantly increased, conversely, serum calcium was significantly decreased in gentamicin injected rats. Similar results were obtained by Hruska et al,(1975) and Burnier et al,(1996).

In conclusion, gentamicin induced nephrotoxicity in rats and the consumption of grape seeds especially oil and extract can improve efficiency of kidney function and the healthy status because of their antioxidant effect. 
Egypt. J. of Nutrition and Health Vol. 9 No. 1 (2014)

Table (1):

Elementary chemical composition of grape seeds sample $(\mathrm{g} / 100 \mathrm{~g})$.

\begin{tabular}{|c|c|c|c|c|c|}
\hline Chem. Comp. & Moisture & Ash & Protein & Fat & Carbohydrates \\
\hline Grape Seeds & $5.98 \pm 0.14$ & $2.62 \pm 0.17$ & $7.51 \pm 0.52$ & $18.23 \pm 0.47$ & $65.66 \pm 0.22$ \\
& & & & & \\
\hline
\end{tabular}

Each value is the mean of three replicates $\pm S D$.

Table (2):

Nutritional indicators of normal control and renal damage rat groups treated with grape seeds powder, extract and oil .

\begin{tabular}{|c|c|c|c|c|c|}
\hline Groups & $\begin{array}{l}\text { Initial weight } \\
\text { (g) }\end{array}$ & $\begin{array}{l}\text { Final weight } \\
\text { (g) }\end{array}$ & $\begin{array}{l}\text { Weight gain } \\
\text { (g) }\end{array}$ & Food intake(g) & FER \\
\hline Normal control (-ve) & $141.67 \pm 1.52^{a}$ & $191.33 \pm 4.16^{b c}$ & $51.00 \pm 2.64^{a}$ & $16.84 \pm 0.23^{a b}$ & $0.049 \pm 0.002^{a b}$ \\
\hline Positive control (+ve) & $144.00 \pm 2.64^{a}$ & $163.00 \pm 5.56^{d}$ & $22.67 \pm 4.50^{b}$ & $15.33 \pm 0.32^{b}$ & $0.025 \pm 0.004^{c}$ \\
\hline grape seeds powder & $143.67 \pm 4.04^{a}$ & $184.00 \pm 2.64^{c}$ & $50.00 \pm 6.08^{a}$ & $16.70 \pm 0.32^{b}$ & $0.049 \pm 0.005^{a b}$ \\
\hline grape seeds extract & $147.33 \pm 3.78^{a}$ & $200.00 \pm 5.29^{a b}$ & $45.67 \pm 2.08^{a}$ & $16.72 \pm 0.04^{b}$ & $0.044 \pm 0.001^{b}$ \\
\hline grape seeds oil & $145.00 \pm 2.00^{\mathrm{a}}$ & $200.67 \pm 5.68^{a}$ & $51.67 \pm 1.52^{a}$ & $17.32 \pm 0.38^{a}$ & $0.053 \pm 0.003^{a}$ \\
\hline
\end{tabular}

Mean values in each column having different superscript (a, b, c, d) are significant. Means with the same letter are insignificantly different. 
Table (3):

Effect of grape seeds powder, extract and oil on some renal functions parameters of the experimental rat groups.

\begin{tabular}{|c|c|c|c|c|c|c|c|}
\hline va & $\begin{array}{c}\text { Creatinine } \\
(\mathrm{mg} / \mathrm{dl})\end{array}$ & $\begin{array}{l}\text { Urea } \\
\text { (mg/dl) }\end{array}$ & $\begin{array}{l}\text { Uric acid } \\
(\mathrm{mg} / \mathrm{dl})\end{array}$ & $\begin{array}{l}\text { Total protein } \\
\text { (g/dl }\end{array}$ & $\begin{array}{l}\text { Albumin } \\
\text { (g/dl) }\end{array}$ & $\begin{array}{l}\text { Globulin } \\
\text { (g/dl) }\end{array}$ & $A / G$ ratio \\
\hline Normal control (-ve) & $0.68 \pm 0.01^{d}$ & $27.65 \pm 1.32^{\text {cd }}$ & $2.78 \pm 0.06^{d}$ & $8.05 \pm 0.051^{b}$ & $4.52 \pm 0.12^{a}$ & $3.53 \pm 0.07^{c}$ & $1.28 \pm 0.06^{b}$ \\
\hline Positive control (+ve) & $2.07 \pm 0.02^{a}$ & $72.12 \pm 1.95^{a}$ & $5.87 \pm 0.05^{a}$ & $5.11 \pm 0.078^{e}$ & $3.19 \pm 0.02^{d}$ & $1.86 \pm 0.06^{d}$ & $1.64 \pm 0.07^{\mathrm{a}}$ \\
\hline grape seeds powder & $0.79 \pm 0.02^{b}$ & $40.52 \pm 0.78^{b}$ & $3.62 \pm 0.04^{b}$ & $7.60 \pm 0.042^{d}$ & $3.73 \pm 0.11^{c}$ & $3.90 \pm 0.09^{b}$ & $0.95 \pm 0.04^{c}$ \\
\hline grape seeds extract & $0.74 \pm 0.02^{b c}$ & $29.18 \pm 1.13^{c}$ & $3.06 \pm 0.05^{c}$ & $7.90 \pm 0.020^{c}$ & $3.95 \pm 0.04^{b}$ & $3.87 \pm 0.03^{b}$ & $1.03 \pm 0.01^{c}$ \\
\hline grape seeds oil & $0.71 \pm 0.01^{\text {cd }}$ & $26.23 \pm 0.67^{d}$ & $2.33 \pm 0.03^{\mathrm{e}}$ & $8.17 \pm 0.070^{\circ}$ & $4.07 \pm 0.04^{b}$ & $4.11 \pm 0.03^{a}$ & $0.98 \pm 0.00^{c}$ \\
\hline
\end{tabular}

Mean values in each column having different superscript (a, b, c, d) are significant. Means with the same letter are insignificantly different. 
Table (4):

Effect of grape seeds powder, extract and oil on SOD, GPX, GST, CAT and MDA

in kidney tissue of the experimental rat groups.

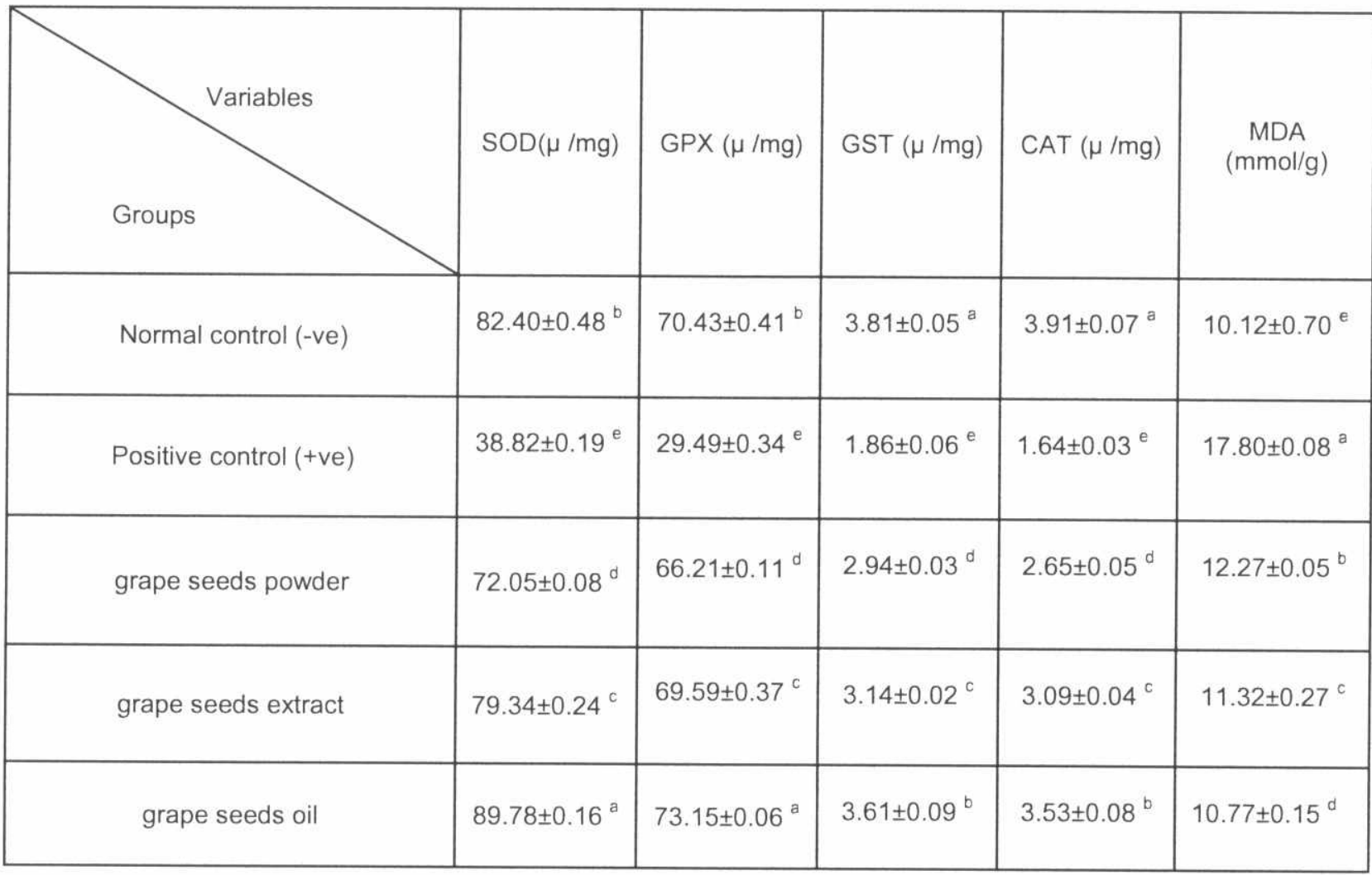

Mean values in each column having different superscript (a, b, c, d) are significant. Means with the same letter are insignificantly different. 
Table (5):

Effect of grape seeds powder, extract and oil on serum renin, erythropoietin (EPO) renal hormone and vitamin $\mathrm{D}$ of the experimental rat groups.

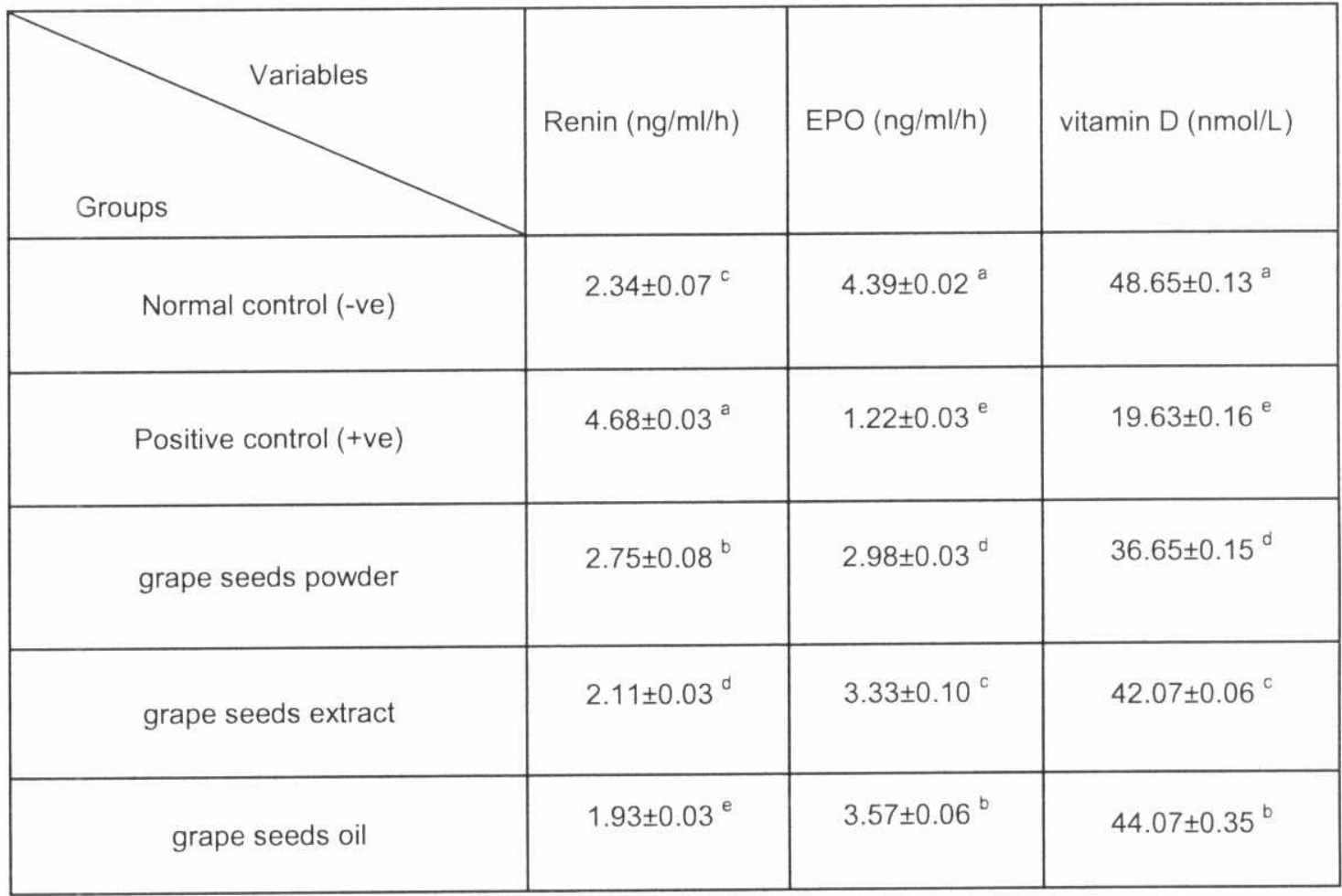

Mean values in each column having different superscript (a, b, c, d) are significant. Means with the same letter are insignificantly different. 
Egypt. J. of Nutrition and Health Vol. 9 No. 1 (2014)

Table (6):

Effect of grape seeds powder, extract and oil on serum $\mathrm{Ca}, \mathrm{P}$ and $\mathrm{K}$ of the experimental rat groups.

\begin{tabular}{|c|c|c|c|}
\hline Variables & $\mathrm{Ca}(\mathrm{mg} / \mathrm{dl})$ & $P(\mathrm{mg} / \mathrm{dl})$ & $\mathrm{K}(\mathrm{mg} / \mathrm{dl})$ \\
\hline Normal control (-ve) & $12.34 \pm 0.80^{a}$ & $4.15 \pm 0.33^{d}$ & $40.65 \pm 0.53^{c}$ \\
\hline Positive control (+ve) & $8.48 \pm 0.60^{b}$ & $8.60 \pm 0.40^{a}$ & $65.84 \pm 0.55^{a}$ \\
\hline grape seeds powder & $9.67 \pm 0.68^{b}$ & $6.23 \pm 0.69^{b}$ & $44.97 \pm 0.42^{b}$ \\
\hline grape seeds extract & $9.30 \pm 0.62^{b}$ & $5.47 \pm 0.49^{b c}$ & $44.48 \pm 0.43^{b}$ \\
\hline grape seeds oil & $10.45 \pm 0.52^{a b}$ & $4.84 \pm 0.45^{c d}$ & $40.51 \pm 0.61^{c}$ \\
\hline
\end{tabular}

Mean values in each column having different superscript (a, b, c, d) are significant. Means with the same letter are insignificantly different. 


\section{References}

Abdelgawad, A.F., M.A .,Desouky., M, El-Neama, El-Fatih.and A.M, Wissam, (2012):

Effect of grape seed extract on oxidative damages in gamma irradiated rats. The Egyp J Hosp Med, 48: 414428.

Abd El-Wahab ,A., El-Adawi, H. and kassem ,H.S .(2008):

Towards understanding the hepatoprotective effect of grape seeds extract on cholesterol-fed rats. Aust. J. Basic Applied Sci., 2: 412-417.

Alia, M.C., Horcajo, L .,Bravo .and L, Goya, (2003):

Effect of grape antioxidant dietary fiber on the total antioxidant capacity and the activity of liver antioxidant enzymes in rats. Nutr Res, 23: 1251-67.

O. A. C., (2000):

Association of Official Agricultural Chemists. Official Method of Analysis. 17th Ed. Vol. 11. Washington U.S. A.

Ardevol, A., Blade, C., Salvado, M.J .and Arola, L. (2000):

Changes in lipolysis and hormone-sensitive lipase expression caused by procyanidins in 3T3-L1 adipocytes. Int. J. Obes. Relat. Metab. Disord. , 24: 319-324.

Ariga ,T. (2004): The antioxidative function, preventive action on disease and utilization of proanthocyanidins. Biofactors, 21: 197-201.

Ashtiyani, S.C., Najafi, H., Firouzifar ,M.R.and Shafaat ,O .(2013):

Grape seed extract for reduction of renal disturbances following reperfusion in rats. Iran. J. Kid. Diseas. 7(1): 28-35.

Ayatollahi, J. (2005):

Evaluation of knowledge and activities of medical students in the last two years of their education about chemoprophylaxis following contact with infectious diseases. IJCID., 9(26): 54-9.

Bagchi, D., Garg, A., Krohn, R.L., Bagchi, M., Bagchi, D.J., Balmoori, J. and Stohs, S.J. (1998):

Protective effects of grape seed proanthocyanidins and selected antioxidants against TPA-induced hepatic and brain lipid peroxidation and DNA fragmentation, and peritoneal macrophage activation in mice. General Pharmacology ,30 (5): 771-776.

Bagchi, D., Ray, S.D., Bagchi, M., Preuss, H.G. and Stohs, S.J. (2002):

Mechanistic pathways of antioxidant cytoprotection by a novel IH 636 grape seed proanthocyanidin extract. Indian J. Exp. Biol., 6:7:17-26.

Baiges, I., Palmfeldt ,J., Bladãc ,C., Gregersen ,N.and Arola, L .(2010): Lipogenesis is decreased by grape seed proanthocyanidins according to liver proteomics of rats fed a high fat diet. Mol. Cell Proteomics. 9(7): 1499-1513.

Balakumar, P., V.A. Chakkarwar, V., Kumar ,A., Jain, J., Reddy and M. Singh, (2008):

Experimental models for nephropathy. J Renin Angiotensin Aldosterone Syst.,9:189-95.

Balu ,M. P., Sangeetha ,C. Murali, G.and Panneerselvam, (2006):

Modulatory role of grape seed extract on agerelated oxidative DNA damage in central nervous system of rats. Brain Res Bull, 68: 469-73. 
Bartholomev, R.J and A. Delany, (1966):

Proc Aust. Assoc. Biochemists.1, 214.

Barron, L.J.R., Celaa, M.V., Santa-Maria, G.and Corzo, N,( 1988):

Determination of the Triglyceride Composition of Grapes by HPLC. Chromatographia 25(7):609-612.

Beuchamp, C and Fridovich, J. (1971):

Superoxide dismutase. Improved an assay applicable to acrylamide gels. Anal Biochem.44:276-287.

Bonsens, K. E. and D. H. Taussky, (1984):

Determination of serum creatinine.J Chem Inv, 27: 648-660.

Burnier, M., Roch-Ramel ,F and Brunner, H.R. (1996):

Renal effects of angiotensin II receptor blockade in normotensive subjects. Kidney Int., 49: 1787-1790.

Çetin ,A., Kaynar ,L., Kocyigit, I., Hacioglu ,S.K., Saraymen ,R., Öztürk ,A., Orhan, O.and Sagdiç, O .(2008):The effect of grape seed extract on radiation-induced oxidative stress in the rat liver. Turk. J. Gastroenterol. 19(2): 92-98.

Chapman, D.G., R. Gastilla and T.A. Campbell, (1950):

Evaluation of protein in food. I. A. Method for the determination of protein efficiency ratio. Can. J. Biochem. Physio., I (37) 679-686.

Charles, D.J.,Morales, R. and Simon,E. (1993):

Essential oil content and chemical composition of hydroalcoholic extract of fennel, New crops,570-3.

Cohen, G.; Dembuic, D. and Marcus, J. ( 1970):

Measurement of catalase activity in tissue extract. Anal. Biochem., 34, 30-38.

Coles, E. H. (1974):

Veterinary Clinical Pathology. Saunders Company, Philadelphia and London. Beuchamp, C and J. Fridovich, 1971. Superoxide dismutase. Improved assay applicable to acrylamide gels. Anal Biochem.44:276-287.

Dimitris, P., Makrisa, B., George; Boskoub; Nikolaos, K. and Andrikopoulosb .(2007):

content and in vitro antioxidant characteristics of wine industry and other agri-food solid waste extracts. Journal of Food Composition and Analysis, 20:125-132.

Dulundu, E., Ozel, Y., Topaloglu ,U., Toklu, H., Ercan, F., Gedik ,N.and Sener ,G (2007):

Grape seed extract reduces oxidative stress and fibrosis in experimental biliary obstruction. J. Gastroenterol. Hepatol. 22: 885- 892.

EI-Ashmawy, I.M., Saleh ,A.and Salama, O.M. (2007):

Effects of marjoram volatile oil and grape seed extract on ethanol toxicity in male rats. Basic Clin. Pharmacol. Toxicol. 101(5): 320-327.

Farombi, E. and M. Ekor, (2006):

Curcumin attenuates gentamicin-induced renal oxidative damage in rats. Medicine, 44(9): 1443-1448.

Fauconneau, B. C., Tallineau, F. Huguet and A. Piriou, (1995):

Gentamicin-induced kidney damage and lipid peroxidation in rats. Toxicol. Lett., 76: 127-134. 
Nagib, R.M

Ferreira, D. and X.C, Li. (2000):

Oligomeric Proanthocyanidins: Naturally Occurring O-heterocycles. Nat Prod Rep, 17: 193-212.

Finn ,W.F .(1977):

Renal responses to environmental toxins. Environ. Health Perspect. 20: 15-26.

Fisher, R.M., Hoffstedt, J., Hotamisligil, G.S., Thorne, A. and Ryden, M. (2002):

Effects of obesity and weight loss on the expression of proteins involved in fatty acid metabolism in human adipose tissue. Int. J. Obes. Relat. Metab. Disord. 26: 1379-1385.

Fossati, P., L. Prencipe, and G. Berti, (1980):

Use of 3,5 dichloro-2-hydroxybenzene sulfonic acid /4-amlnophenazon chromogenic system in direct enzymatic assay of uric acid in serum and urine. Clin. Chem., 26: 227-231.

Hala, A.H. Khattab. (2012):

Effect of Morin against Gentamicin-Induced Nephrotoxicity in Young Male Rats. The Egyptian Journal of Hospital Medicine .Vol., 49: 705- 717.

Heibashy, M.I.A and Abdel Moneim, A.E. (1999):

Kidney and liver function tests after late dimethyl sulfoxide (DMSO) administration in rats with gentamicin induced acute renal failure. J. Egypt German Soc. Zool., 30(A): 35-48.

Hruska, K.A., KopkIman, R., Rutherford, W.E., Kuahr, S. and Salatopolsky, E. (1975):

Metabolism of immunoactive parathyroid hormone in dog, role of kidney and effects of chronic renal disease.J.Clin. Invest., 56:39-48.

Inoue, S. and S. Kawanishi, (1995):

Oxidative DNA damage induced by simultaneous generation of nitric-oxide and superoxide. FEBS lett., 371: 8688.

Kamel, B.S, Dawson, H., Kakuda, Y. (1985):

Characteristics and composition of melon and grape seed oils and cakes. Journal-of-the-American-OilChemists'Society., 62: 5, 881-883.

Kamphuis, M.M., Mela, D.J. and Westerterp-Plantenga, M.S. (2003):

Diacylglycerides affect substrate oxidation and appetite in humans. Am. J. Clin. Nutr,. 77: 1133-1139.

Langhans, W. and Scharrer, E. (1987):

Evidence for a vagally mediated satiety signal derived from hepatic fatty acid oxidation. J. Auton. Nerv. Syst. 18:13-18.

Laurent ,G., Toubeau ,G., Heuson-Steinnon, J.A., Tulkens, P.and Maldauge, P.(1988):

Kidney tissue repair after nephrotoxic injury:biochemical and morphologic characterization. CRC Crit. Rev. Toxicol. 19: 147-183

Li, Y. C. Kong, J.M.,Wei, Z., Chen, S.,Liu, Q. and L. Cao. (2002):

"1,25-dihydroxyvitamin D3 is a negative endocrine regulator of the renin-angiotensin system," Journal of Clinical Investigation, vol. 110, no. 2, pp. 229-238.

Lopez-Novoa, J.M., Y. Quiros, L. Vicente, A.I. Morales and FJ Lopez-Hernandez, (2011):

New insights into the mechanism of aminoglycoside nephrotoxicity: an integrative point of view. Kidney Int., 79:33-45. 


\section{Egypt. J. of Nutrition and Health Vol. 9 No. 1 (2014)}

Luque-Rodriguez, J.M., Luque de Castro, M.D. and Pierez-Juan, P. (2005):

Extraction of fatty acids from grape seed by superheated hexane. Talanta, 68: 126-130.

Maheswari, U.M.and Rao, P.G .(2005):

Antihepatotoxic effect of grape seed oil in rats. Ind. J. Pharmacol. 37 (3): 179-182.

Maldonadu ,P.D., Barrera, D., Rivero, I., Mata, R., Copos ,O.N.and Pando, R.H. (2003):

Antioxidant S-alllcystein prevents gentamicin-induced oxidative stress and renal damage. Bio med;35:317-24.

Mc-Carty, M.F. and Scharrer, E. (1994):

Promotion of hepatic lipid oxidation and gluconeogenesis as a strategy for appetite control. Med. Hypotheses, 42: $215-225$.

Moran, M.S., J.W. Difierre and B. Manneruik, (1979):

Levels of glutathione reductase glutathiones- transferase in rat lung and liver. Biochim Biophys Acta., 582:6778.

Nakagawa, T., Yokozawa ,T., Sano, M., Takeuchi, S., Kim ,M. and Minamoto, S .(2004):

Activity of (-)-epigallocatechin 3-o-gallate against oxidative stress in rats with adenine-induced renal failure. J. Agric. Food Chem., 52: 2103-2107.

NRC (National Research Council), (1995):

Nutrient requirement of laboratory. Fourth reviser edition. pp: 29-30 National Academy Press Washington, animals, D.C. Environ. Sci. Health, 25: 487-494.

Nykjaer, A ., Schambye ,H., Pedersen, A. H.and Nielsen, H. (2009):

Assessing low-dose gentamicin- induced kidney injury in rats by analysis of urine. J Pharmacol Toxicol Methods.; 60:316-320.

Ohnishi, M., Hirose, S., Kawaguchi, M., Ito, S.and Fujino, Y, (1990):

Chemical Composition of Lipids, Especially Triacylglycerol, in Grape Seeds. Agric. Biol. Chem. 54(4):10351042.

Patton, C.J. and S.R. Crouch, (1977): Enzymatic colorimetric method to determination of urea in serum. Anal. Chem., 49: 464.

Pinheiro ,F.V., Pimentel ,V.C., De Bona, K.S, Scola, G., Salvador ,M., Funchal ,C.and Moretto, M.B (2010): Decrease of adenosine deaminase activity and increase of the lipid peroxidation after acute methotrexate treatment in young rats: protective effects of grape seed extract. Cell Biochem. Funct. 28(1):89-94.

Pupsa, R.S.; Connie, M.W. and April, C.M. ( 1994):

Mineral bioavailability in rats from intrinsically labeled whole wheat flour of various phytate levels.J. Agric. Food Chem., 42(11): 2531-2535.

Purushotham, S., Muthaiya, B., Dayalan, H. and Chinnakannu, P. (2005):

Age associated changes in erythrocyte membrane surface charge: Modulatory role of grape seed proanthocyanidins .Experimental Gerontology ,40:820-828 .

Rao, P.U.( 1994): lipid profile of grape seed oil fractions. Food Chem. 50: 379-383. 
Rice-Evans, C.A.; Miller, N.J. and Praganga, G. (1996):

Structure-antioxidant activity relationships of flavonoids and phenolic acids. Free Radic. Biol. Med. 20: 933956.

Sato, S., Hori, Y., Yamate, J., Saito, T., Kurasaki, M. and Hatai ,A .(2005):

Protective effect of dietry azuki bean (Vigna angularis) seed coats against renal interstitial fibrosis of rats induced by cisplatin. Nutrition, 21: 504-511.

Schuster, W.H , (1992): Ipflanzen in Europa. DLG-Verlag, Frankfurt am Main, 240.

Sehirli, O., Ozel, Y., Dulundu, E., Topaloglu, U., Ercan ,F.and Sener ,G .(2008):

Grape seed extract treatment reduces hepatic ischemia-reperfusion injury in rats. Phytother. Res. 22(1): 43-48.

Seo-Kyung,W., Jung-Soon,Y., Park-Mi,J.g., Song-Yeon,J.and Choung-Se,Y. (2001):

Effects of leucocyanidines on activities of metabolizing enzymes and antioxidant enzymes. Biological-andPharmaceutical-Bulletin. 24(5): 592-593.

Shi, J., Yu,K. and Pohorly, J.Y. (2003):

Polyphenolics in grape seeds-biochemistry and functionality. Journal of Medicinal Foods., 6(4):291-299.

Shin ,M.O., Yoon, S.and Moon ,J.O . (2010):

The proanthocyanidins inhibit dimethylnitrosamine-induced liver damage in rats. Arch. Pharm. Res. 33(1): 167173.

Snedecor, G.W. and Cochran ,W.G,(1967):

Statistical Methods; 7th Ed., The Lowa State University Press., Ames, Lowa, U.S.A.

Stojiljkovic, N, D., Mihailovic, S., Veljkovic, M., Stoiljkovic. and I.Jovanovic, (2008):

Glomerular basement membrane alterations induced by gentamicin administration in rats. Exp Toxicol Pathol., $60: 69-75$.

Sweileh W.M. (2009):

Time course analysis of aminoglycoside-induced elevation of serum creatinine. J Clin Pharm Therp .; 1:5311540.

Tapple, A.L. (1978):

In Glutathione peroxidase and hydroperoxidase methods, in Methods in Enzymology, Vol II. Sidney F., Lester P., editors. Academic Press; New York: 506-513.

Tebib, K., Besancon, P. and Rouanet, J. (1996):

Effects of dietary grape seed tannins on rat cecal fermentation and colonic bacterialenzymes. Nutrition Research, 16 (1): 105-110.

Uchiyama, M. and M. Mihara, (1978): Determination of malondialdhyde precursor in tissues by thiobarbituric acid test. Anal. Biochem., 86 (1),271-278.

Vale'rie, B., P. Alcindo, J. Coste, L. Carinne, C. Sandrine, B. Denis, S. Olivier, L. Catherine, C. Yvon and C. Filome'na, (2006):

Impaired erythropoietin production in liver transplant recipients: the role of calcineurin inhibitors. Liver transplantation, 12: 1649-1654.

Van-Kats, J., Methot, D., Paradis, P., Silversides, D. and Reudelhuber, T. (2001):

Use of a biological peptide pump to study chronic peptide hormone action in transgenic mice: direct and indirect effects of angiotensin II on the heart. J. Biol. Chem., 276: 44012-44017. 


\section{Egypt. J. of Nutrition and Health Vol. 9 No. 1 (2014)}

Weichselbaum, T.F. (1946):

An accurate and rapid method for the determination of protein in small amount of blood serum and plasma. Am $\mathrm{J}$ Clin Path, (16):40.

Wiesenfeld ,H.C.and Heine, R.P. (1998):

The use of once-daily dosing of gentamicin in obstetrics and gynecology. Infect Dis Obstet Gynecol.; 6:155-159.

Wilkie, J.B., S.W. Jones and O.L. Kline, (1958):

Determination of vitamin D by a chemical method involving chromatography and color inhibition. Journal of the American Pharmaceutical Association, 47(6): 385-394.

Yamabe, N., Yokozawa ,T., Oya, T. and Kim, M. (2006):

Therapeutical potential of (-)-epigallocatechin 3-o-gallate on renal damage in diabetic nephropathy model rats. J. Pharmacol. Exp. Ther., 319: 228-236.

Yang, C., X. Du, and Y. Han, (1995):

Renal cortical mitochondria are the source of oxygen free radicals enhanced by gentamicin. Ren Fail., 17: 2126.

Yousef ,M.I., Saad ,A.A.and El-Shennawy, L.K. (2009):

Protective effect of grape seed proanthocyanidin extract against oxidative stress induced by cisplatin in rats. Food Chem.Toxicol., 47:1176-1183.

Yuan, W.,W. Pan, J. Kong et al., (2007):

"1,25-dihydroxyvitamin D3 suppresses renin gene transcription by blocking the activity of the cyclic AMP response element in the renin gene promoter," The Journal of Biological Chemistry, vol. 282, no. 41, pp. $29821-29830$.

Zhang, Z. ,L. Sun, Y.Wang et al., (2008):

Renoprotective role of the vitamin D receptor in diabetic nephropathy, Kidney International, vol. 73 , no. 2, pp. $163-171$.

Zhang, Y., J. Kong, D. K. Deb, A. Chang, and Y. C. Li,( 2010):

"Vitamin D receptor attenuates renal fibrosis by suppressing the renin-angiotensin system," Journal of the American Society of Nephrology, vol. 21, no. 6, pp. 966-973. 


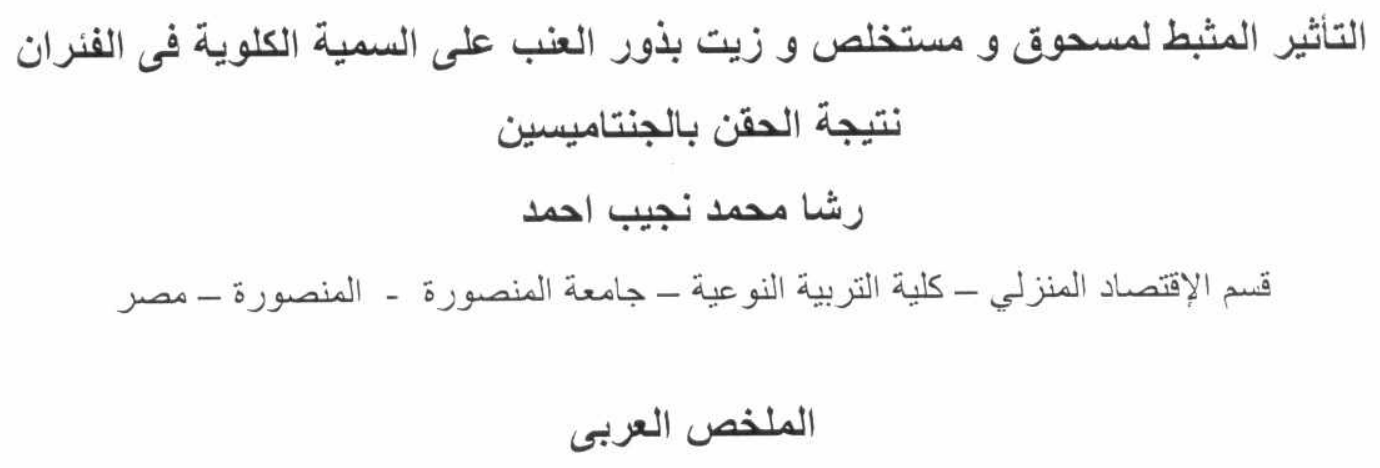

